\title{
Get excess salt out of our diet
}

$\mathrm{O}$ nce a commodity of exchange, salt is now a commodity of disease and death. We underestimate how much excess salt we eat and how much harm it can do. The greatest harm comes from high blood pressure and its consequences. Of the estimated 1 billion people living with hypertension, ${ }^{1}$ about $30 \%$ can attribute it to excess salt intake. ${ }^{2}$ Salt-related blood pressure elevation accounts for about $14 \%$ of strokes and $9 \%$ of myocardial infarctions. ${ }^{3}$

How much salt we need for good health is probably close to the natural salt content of unprocessed food, about $0.5 \mathrm{~g}$ per day. Instead, the average person in industrialized countries consumes about $10 \mathrm{~g}$ (1.5 teaspoons) daily, about $75 \%$ of which is from processed food. ${ }^{4}$ In contrast, the Yanomami Indians of the Amazon eat less than $1 \mathrm{~g}$ of salt a day. They also do not have any hypertension, even with aging. Their children do not experience the rapid rise in blood pressure at puberty that occurs in children elsewhere. At the other extreme, Japanese people eat about $15 \mathrm{~g}$ of salt daily. Despite being one of the world's healthiest nations overall, they have high rates of hypertension and the highest rate of stroke in the industrialized world.

Added salt in our diet isn't necessary. Physiologically important sodium loss occurs with normal activities only if there is prolonged sweating (e.g., continuous running for longer than $90 \mathrm{~min}$ ). Despite widespread use of sodium salts in recipes, they are essential only when sodium bicarbonate is required for "rising." Refrigeration has largely replaced the need for sodium salts as food preservatives. Moreover, people who forego added salt commonly observe that unique and interesting flavours of unsalted food emerge.

Those without high blood pressure might comfort themselves with the belief that salt intake is unimportant. But the relation between blood pressure and dietary salt intake, though modest and heterogeneous in the middle ranges, is continuous rather than binary. In industrialized societies, the prevalence of hypertension increases continuously with age, suggesting that if we continue with our current salt intake, most of us will become hypertensive if we live long enough. However, reduction of dietary salt by a median of $4.4 \mathrm{~g}$ per day lowers blood pressure among both hypertensive and normotensive populations. ${ }^{5}$ Also, 2 long-term clinical trials of individuals with high normal blood pressure found that an average reduction of salt intake by $2.4 \mathrm{~g}$ per day led to absolute decreases of $2.5 \%$ in cardiovascular events and $2.4 \%$ in allcause mortality. ${ }^{6}$

Reduction of salt intake is an important cornerstone of hypertension management. Although targeting such high-risk individuals seems appealing, reducing salt intake across the entire population over a lifetime is likely to be more effective, because even a small downward shift of the population's blood pressure distribution curve would prevent far more cardiovascular events. For Canada, salt reduction could decrease hypertension prevalence from 3.5 million to 2.2 million. ${ }^{2}$

The magnitude of the potential health consequences lends urgency to removing a risk that confers little apparent benefit. Action is needed. Physicians can advocate for change from food processing and restaurant industries: much less salt in food preparation and clear content labelling on packages and menus. Physicians can also counsel patients to minimize consumption of processed and preserved food and to refrain from adding more salt. No added salt in the diet appears to be a safe ideal. The maximum daily salt intake should be $2.8 \mathrm{~g}$ for active young people who sweat more and $2.2 \mathrm{~g}$ for older people. ${ }^{7}$

Consumers shouldn't wait for more advice. They should read labels on processed food items and avoid those with high salt content (a reasonable threshold is $20 \mathrm{mg}$ of sodium per serving), demand low salt food in stores and restaurants, and complain when salt overwhelms the taste. We should not be forced to eat salt. The correct default should be no added salt in food we purchase, leaving those who still wish to do so free to indulge at their own risk.

Ken Flegel MDCM MSc

Senior Associate Editor

Peter Magner MD

Associate Editor, Research

CMAJ

With the Editorial-Writing Team (Paul C. Hébert MD MHSc, Matthew B. Stanbrook MD PhD, Barbara Sibbald BJ, Noni MacDonald MD MSc and Amir Attaran LLB DPhil)

Competing interests: See www.cmaj.ca/misc/edboard.shtml.

\section{REFERENCES}

1. American Heart Association. Heart disease and stroke statistics: 2008 update at-aglance. Dallas (TX): The Association; 2008. Available: www.americanheart.org /downloadable/heart/1200082005246HS_Stats\%202008.final.pdf (accessed 2008 Dec. 22).

2. Joffres MR, Campbell NRC, Manns B, et al. Estimates of the benefit of a populationbased reduction in dietary sodium additives on hypertension and its related health care costs in Canada. Can J Cardiol 2007;23:437-43.

3. Whelton PK, He J, Apple LJ, et al.; National High Blood Pressure Education Program Coordinating Committee. Primary prevention of hypertension: clinical and public health advisory from The National High Blood Pressure Education Program. JAMA 2002;288:1882-8.

4. Mattes RD, Donnelly D. Relative contributions of dietary sodium sources. $J$ Am Coll Nutr 1991;10:383-93.

5. He FJ, MacGregor GA. Effect of longer-term modest salt reduction on blood pressure. Cochrane Database Syst Rev 2004;(3):CD004937.

6. Cook NR, Cutler JA, Obarzanek E, et al. Long term effects of dietary sodium reduction on cardiovascular disease outcomes: observational follow-up of the trials of hypertension prevention (TOHP). BMJ 2007;334:885-93.

7. Khan NA, Hemmelgarn B, Herman RJ, et al. The 2008 Canadian Hypertension Education Program recommendations for the management of hypertension: part 2 — therapy. Can J Cardiol 2008;24:465-75. 